\title{
MEN1 c.825-1G >A mutation in a family with multiple endocrine neoplasia type 1: A case report
}

\author{
ZHIWEI NING ${ }^{1,2}$, OU WANG $^{1}$, XUNWU MENG $^{1}$, XIAOPING XING $^{1}$, \\ WEIBO XIA $^{1}$, YAN JIANG ${ }^{1}$, MEI LI $^{1}$ and YUAN XU ${ }^{2}$ \\ ${ }^{1}$ Department of Endocrinology, Peking Union Medical College Hospital, Peking Union Medical College, Beijing 100730; \\ ${ }^{2}$ Department of Endocrinology, Beijing Chaoyang Hospital, Capital Medical University, Beijing 100020, P.R. China
}

Received October 8, 2014; Accepted July 17, 2015

DOI: $10.3892 / \mathrm{mmr} .2015 .4138$

\begin{abstract}
Multiple endocrine neoplasia type 1 (MEN1) is an autosomal dominant disease characterized by combined occurrence of tumors and hyperplasia in tissues including the parathyroid, gastrointestinal endocrine tissue and anterior pituitary. Heterozygous germline mutation of the tumor suppressor gene MEN1 is the cause of the disease. Treatment and long-term follow up of patients with MEN1 are rarely reported in the literature due to the relative rarity of the disease; thus, there is limited understanding of tumor biology and behavior, and heterogeneous clinical presentation. This case report observed a family that presented with MEN1 c.825-1G>A mutation. The clinical features and treatment were followed up for $>20$ years. Detailed family history of this pedigree was investigated and followed up. Genomic DNA was extracted by standard methods from peripheral leukocytes. The coding sequence, including 9 coding exons and 16 splice junctions of the MEN1 gene of leukocyte DNA was determined. The proband presented with gastrinoma, pituitary tumors, hyperparathyroidism, thymoma and lung carcinoid tumors, and was followed from age 35 to 54 years old. During the 20 years, the patient underwent four surgeries: Trans-sphenoidal adenomectomy, followed by post operative radiotherapy at 39 years; hyperplasia parathyroid gland resection at 40 years; removal of pancreatic, head and neck, duodenal, gallbladder, bile duct, subtotal gastric (4/5) and pyloric region lymph nodes at age 41 ; and a thymectomy and left lung carcinoid tumor removal procedure at the age of 49. The patient died of unrelated trauma and had a relatively stable illness course. DNA sequence analysis revealed MEN1 gene c.825-1G $>$ A or IVS 5-1G $>$ A mutation in the family.
\end{abstract}

Correspondence to: Dr Zhiwei Ning, Department of Endocrinology, Beijing Chaoyang Hospital, Capital Medical University, 8 Gongtinan Road, Beijing 100020, P.R. China

E-mail: ningzhiwei@hotmail.com

Key words: multiple endocrine neoplasia type 1, MEN1, mutation, treatment, follow up
Two carriers in the pedigree were identified and followed up. Data indicated that although MEN1 is a complex disease involving multiple organs and systems, MEN1 tumors should be considered surgically curable. If patients are properly cared for by multidisciplinary teams comprising of relevant specialists with experience in the diagnosis and treatment of patients with endocrine tumors, patients may have a relatively positive prognosis.

\section{Introduction}

Multiple endocrine neoplasia type 1 (MEN1) is an autosomal dominant disease characterized by combined occurrence of tumors/hyperplasia in the parathyroid gland, gastrointestinal endocrine tissue, anterior pituitary and other tissues. The responsible gene, $M E N 1$, has been mapped to chromosomal region 11q13 $(1,2)$. The gene is composed of 10 exons and encodes a 610 -amino acid protein (MENIN) $(1,2)$. It is hypothesized to be involved in cell growth regulation, cell cycle, genome stability and synapse plasticity. A two-hit mutation hypothesis in this gene proposes that the first hit or mutation is inherited as a germline mutation and the second hit occurs as a somatic mutation in the predisposed endocrine cell (3). This second mutation may occur by chromosome loss (e.g. loss of heterozygosity), chromosome loss with duplication, mitotic recombination or another localized event, such as a point mutation. As a consequence of these two mutations, both alleles of the MEN1 gene are inactivated, allowing tumor growth $(3,4)$. Germline mutations of the MEN1 gene were detected to be inherited or sporadic in patients affected by MEN1-like tumors (5). Although MEN1 is a rare disease with an estimated prevalence of 30-200 per million, the penetration rate is high among MEN1 gene carriers. Preexisting evidence demonstrated that all carriers were completely exposed by 50 years of age (6).

Although >1,000 families presenting with MEN1 have been described since the cloning of the gene in 1997 (7), the clinical treatment and long term follow-up is rarely reported in the literature (8). This case describes a Chinese family presenting with MEN1, with a mutation in intron 5 of the MEN1 gene, which has not been described previously. After four surgical procedures and full follow up over 20 years, the proband showed a relatively benign prognosis. 


\section{Case report}

Ethical approval. Written informed consent was obtained from the proband, her relatives and the 75 healthy controls prior to genetic testing. This study was approved by the ethics committee of Peking Union Medical College Hospital (Beijing, China). Written informed consent was obtained from study participants or the caretakers or guardians of the minors involved in this study. All clinical investigations were conducted according to the principles expressed in the Declaration of Helsinki.

Proband (III-3) patient history. The proband (III-3), a female, was born in a family native to Benxi, Liaoning Province of China in July 1953. The patient complained of diarrhea and upper abdominal pain since the age of 30. At the age of 32, the patient presented with galactorrhea, secondary amenorrhea, extremity and back pain, and gross hematuria. She first consulted the Peking Union Medical College Hospital in March 1988 when she was 35 years old. Gastroscopic investigation revealed multiple ulcers of the duodenal bulb and post bulbar area. Endocrine investigation revealed a serum gastrin level in the fasting state of 550-950 pg/ml (reference range, $20-160 \mathrm{pg} / \mathrm{ml}$ ). The ratio of basic acid output (reference range $3.9 \pm 1.98 \mathrm{mmol} / \mathrm{h}$ ) and maximal acid output was 25.2 (reference range $3-23 \mathrm{mmol} / \mathrm{l}$ ), with a ratio of $63.5 \%$. Serum prolactin was $125 \mathrm{ng} / \mathrm{ml}$ (reference range, $1.5-11.5 \mathrm{ng} / \mathrm{ml}$ ). Computer tomography scans showed pituitary macroadenomas that were less enhanced by the contrast agent, $3 \times 3 \times 2.5 \mathrm{~cm}$ in size, in the pituitary region. The serum calcium level was 9.6-10.7 mg/dl (reference range 8.4-10.4 mg/dl), and phosphate level was 3.0-4.0 mg/dl (reference range 3.0-5.0 mg/dl). Urine calcium excretion ( $24 \mathrm{~h}$ ) was $310 \mathrm{mg}$ (reference range, $<300 \mathrm{mg}$ ) and serum parathyroid hormone was elevated to $37.2 \mathrm{ng} / \mathrm{dl}$ (radioimmunoassay normal range, $<27 \mathrm{ng} / \mathrm{dl}$ ). X-ray and ultrasonography did not reveal the presence of kidney stones. The patient was was diagnosed with MEN1 gastrinoma, a pituitary tumor and primary hyperparathyroidism. Surgical treatment was refused by the patient and $20 \mathrm{mg} /$ day of omeprazole was administered, which relieved diarrhea and upper abdominal pain.

In the following 2 years, the patient complained of headaches and her visual field was restricted in her left eye. She accepted a trans-sphenoidal adenomectomy in May 1992 (at 38 years of age) in the Peking Union Medical College Hospital. The tumor was $3 \times 3 \times 3 \mathrm{~cm}$ in size and sella tursica basement invasion was identified; the tumor was histological diagnosed as sparsely granulated cell nonfunctional adenoma. Radiotherapy was also administered post surgery at a dose of $5,000 \mathrm{rads} /$ month. Following treatment, the patient's menstrual periods resumed, headaches were relieved and thyroid function test results were normal. In addition, the level of adrenocorticotropic hormone was $<13 \mathrm{pg} / \mathrm{ml}$ (reference range $25-50 \mathrm{pg} / \mathrm{ml}$ ); $24 \mathrm{~h}$ urine free cortisol level was $25.8 \mu \mathrm{g}$ (reference range $60 \pm 3.5 \mu \mathrm{g} / 24 \mathrm{~h}$ ); serum gastrin was $180 \mathrm{pg} / \mathrm{ml}$ (reference range $50-150 \mathrm{pg} / \mathrm{ml}$ ); parathyroid hormone was $36.8 \mathrm{ng} / \mathrm{dl}$ (radioimmunoassay normal range $<27 \mathrm{ng} / \mathrm{dl}$ ); serum free calcium ion was $1.31 \mathrm{mmol} / 1$ (normal range, $1.1-1.2 \mathrm{mmol} / \mathrm{l}$ ) and total serum calcium was $10.7 \mathrm{mg} / \mathrm{dl}$ (reference range 2.25-2.75 mmol/l). ${ }^{131} \mathrm{I}-\mathrm{MIBI}$ revealed a radioactivity-dense area in the upper and lower thyroid area.
In September 1993, at 39 years old, the patient underwent a second surgical procedure because of elevated serum calcemia and hyperparathyroidism. All four parathyroid glands were found to be enlarged. All the right side and half of each of the two left side parathyroid glands $(2+1 / 2+1 / 2)$ were resected, which resulted in normalization of serum calcium and phosphate levels.

At 40 years old, the patient underwent the advised pancreatoduodenectomy (whipple procedure) to treat the gastrinoma. The pancreatic head and neck, duodenal, gallbladder, bile duct, subtotal gastric (4/5) and pyloric region lymph nodes were removed. Pathological investigation showed infra-duodenal mucosa and multiple pancreatic neuroendocrine neoplasias, immunohistochemical analysis revealed positive cell nuclear staining of gastrin, chromogranin A and neuron-specific enolase, and negative staining of 5 hydroxytryptamine, pancreatic polypeptide and glucagon; lymph node metastases were located in $7 / 21$.

At the age of 45, the patient was diagnosed with diabetes and insulin treatment was initiated. Thymoma and lung masses in her left lung were identified at the age of 46; thus, a fourth surgical procedure was conducted in December 2002. The whole thymus and one lobe of the left lung were removed from the patient. Pathological investigation revealed a malignant carcinoid tumor in the thymus and left lung with lymph nodes metastasis. Immunohistological analysis revealed that these masses were positively stained for cytokeratin AE1/AE3 and negatively stained for chromogranin A and Syn.

The proband, who had poorly-controlled diabetes, died of cerebral hemorrhage after severe accidental trauma in December 2007 at the age of 54 .

Family history. The pedigree of this family is shown in Fig. 1. Five members (III-3, III-5, IV-1, IV-2 and IV-3) of the family were screened. In order to confirm the presence of the mutation in the family, 75 healthy controls from a health checkup population were also enrolled in the present study. A detailed illness and family history were taken; pituitary, primary parathyroiddism, hypertension, peptic ulcer history and family history were negative. Detailed family history and venous blood samples were first studied in May 2003. The patient's grandfather (I-1) succumbed to severe stomach disease at 84 years old. Her father (II-1) was diagnosed with gastrinoma and underwent surgery at 56 years old, he succumbed to malignant thymoma at 70 years old. An uncle (II-3) succumbed to stomach disease and kidney stones. An aunt (II-5) had kidney stones, and her daughter (III-15) had nonfunctional pituitary adenoma and underwent surgery at the Peking Union Medical College Hospital at the age of 36 years old in 1986. The brother of the proband (III-1) succumbed to gastrinoma of the pancreas, malignant thymoma with lymph node, brain and bone metastasis at the age of 55. The proband's sister (III-5) was 47 years old in 2003, her two nieces (IV-1 and IV-3) were 23 and 20 years old, respectively and her daughter (IV-2) was 20 years old; all four were in good health.

MEN1 gene mutation analysis. Genomic DNA was extracted by standard methods from peripheral leukocytes. The coding sequence, including 9 coding exons and 16 splice junctions of the MEN1 gene of leukocyte DNA, was determined. DNA 
Table I. Laboratory findings of IV-2 tested in March 2003 and March 2012.

\begin{tabular}{lccc}
\hline Clinical observation & Reference range & March 2003 & March 2012 \\
\hline Hemoglobin $(\mathrm{g} / \mathrm{l})$ & $110-150$ & 135 & 4.2 \\
Red blood cells $\left(\mathrm{x} 10^{12} / \mathrm{l}\right)$ & $3.5-4.5$ & 28.2 & 3.4 \\
ACTH $(\mathrm{pg} / \mu \mathrm{l})$ & $25.0-65.0$ & 3.5 & 32.0 \\
Plasma Glucose $(\mathrm{mmol} / \mathrm{l})$ & $3.1-6.4$ & 5.1 & 4.5 \\
Insulin $(\mu \mathrm{U} / \mathrm{ml})$ & $2.6-24.9$ & 2.35 & 6.1 \\
Serum calcium $(\mathrm{mmol} / \mathrm{l})$ & $2.15-2.55$ & 1.12 & 2.45 \\
Serum phosphorus $(\mathrm{mmol} / \mathrm{l})$ & $0.87-1.45$ & 68 & 1.01 \\
Alkaline phosphatase $(\mathrm{IU} / \mathrm{l})$ & $40-150$ & 92 & 108 \\
Parathyroid hormone $(\mathrm{pg} / \mathrm{ml})$ & $15.0-65$ & 15 & 167 \\
PRL $(\mathrm{ng} / \mu \mathrm{l})$ & $3.4-24.1$ & 0.39 \\
TSH $(\mu \mathrm{IU} / \mu \mathrm{l})$ & $0.30-3.9$ & 80 & 23.0 \\
Gastrin $(\mathrm{pg} / \mathrm{ml})$ & $50-150$ & 0.7 \\
GH $(\mathrm{ng} / \mu \mathrm{l})$ & $0-2$ & 0.45 \\
\hline
\end{tabular}

ACTH, adrenocorticotropic hormone; PRL, prolactin; TSH, thyroid stimulating hormone; GH, growth hormone.

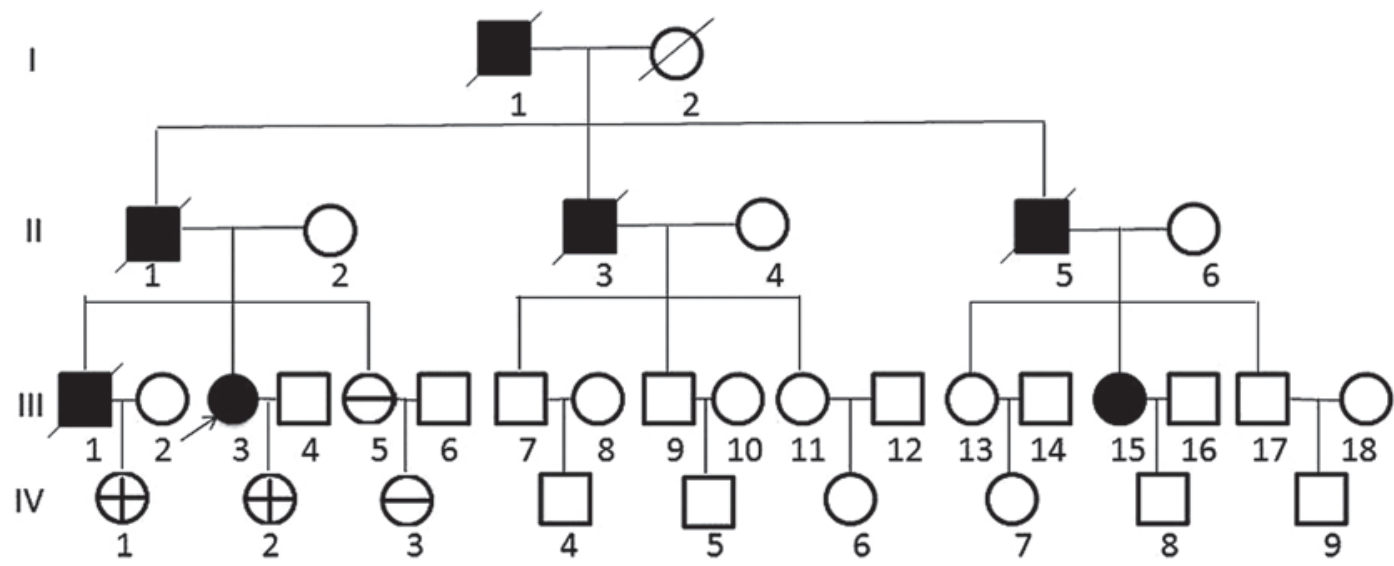

Figure 1. Pedigree of a family with MEN1. Generations available for study are indicated by Roman numerals I, II, III and IV. Black symbol, affected subjects; square, male; circle, female. / indicates a deceased individual at the time of the investigation, and the arrow indicates the presence of a proband. + in circle, $M E N 1$ mutation carrier; - in circle, negative in MEN1 mutation gene test.

fragments ranging from 240 to 393 bp in length were amplified from leukocyte DNA, genomic DNA was amplified in the presence of $75 \mathrm{ng}$ of each oligonucleotide primer and 1.5 units of pfu Taq polymerase (Tianwei, Beijing, China) in a final volume of $50 \mathrm{ml}$ of the following solution: $0.5 \mathrm{mmol} / 1 \mathrm{deoxy}-$ nucleotide triphosphates, 1 or $2 \mathrm{mmol} / 1 \mathrm{MgCl}_{2}, 67 \mathrm{mmol} / \mathrm{l}$ Tris (pH 8.8), $16.6 \mathrm{mmol} / \mathrm{l}$ ammonium sulfate, $6.7 \mathrm{mmol} / 1$ EDTA and $10 \mathrm{mmol} / 12$-mercaptoethanol. The primer sequences used were as previously described $(9,10)$, derived from the DNA sequence (Genbank accession no. U93237) and synthesized by Shanghai Bioasia (Shanghai,China). Amplification proceeded by a denaturation step of $5 \mathrm{~min}$ at $95^{\circ} \mathrm{C}$, followed by 33 cycles of $1 \mathrm{~min}$ at $95^{\circ} \mathrm{C}, 2 \mathrm{~min}$ at $55^{\circ} \mathrm{C}$ and $3 \mathrm{~min}$ at $72^{\circ} \mathrm{C}$, and a final extension step of $8 \mathrm{~min}$ at $72^{\circ} \mathrm{C}$ using a PTC-150 Thermocycler (MJ Research, Inc., St. Bruno, QC, Canada). PCR products were purified with $2 \%$ agarose gel electrophoresis and sequenced with Sanger dideoxy chain termination (Shanghai Bioasia;), The sequences obtained were matched with the published
MEN1 gene (Genbank accession no. U93237). The entire coding region of the $M E N 1$ gene, including the exon-intron boundaries, was sequenced. The direct DNA sequencing results of the proband (III-3) revealed heterozygous $G$ to $A$ variation at the nucleotide position-1 of intron 5 (c.825-1G>A or IVS5-1G>A. DNA mutations in the MEN1 gene were not observed in the 75 healthy controls (Fig. 2). No other mutations were found in the coding regions and the exon-intron boundaries regions. The heterozygous germline mutation was also identified in the patient's daughter (IV-2) and one niece (IV-1), but not in another niece (IV-3).

Follow up. Familial history in 2003 revealed that the sister (III-5), nieces (IV-1 and IV-3) and daughter (IV-2) of the proband were clinically normal, with negative history of stomach disease, kidney stones, menstrual disorders, hypertension, lipoma and other endocrine disorders. In addition, serum calcium, phosphate and alkaline phosphatase levels were all normal. 


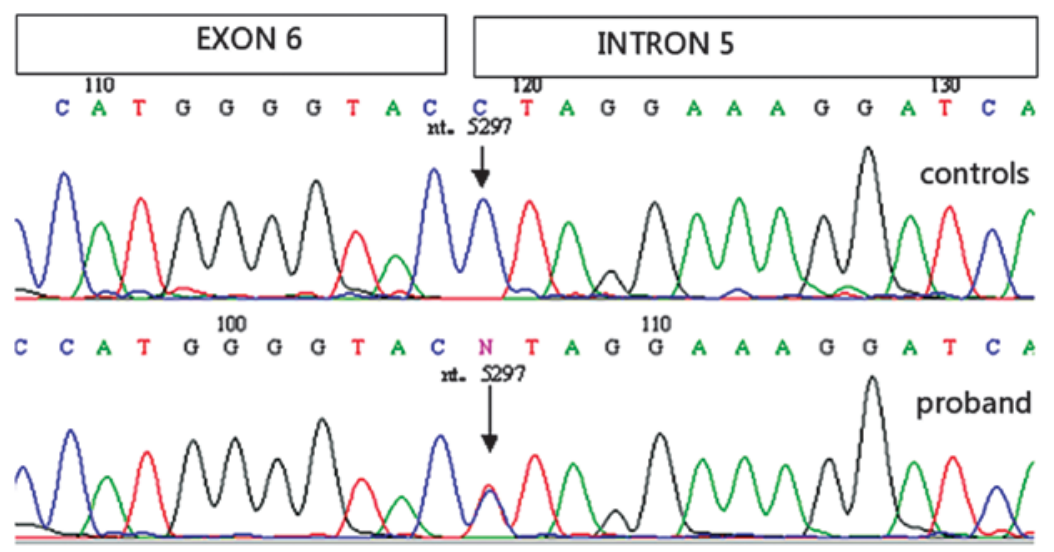

Figure 2. Final nucleotide of intron 5, guanine, is substituted with adenine in one of the alleles.

For private reasons, one carrier (IV-1), who was 32 years old and fathered one child in 2012, was not accepted for further investigation.

The final follow up occurred in March 2012, the family history was provided by the proband's sister (III5) and her daughter (IV-2). The proband's daughter (IV-2) had 2 sons (7 years old and 7 months old in 2012). She was in good health except from mild anemia, with no complaints of stomach pain, hypoglycemia or bladder stones. The laboratory findings are summarized in Table I. The patient was observed to have an elevated serum parathyroid hormone level and normal serum calcium level; however, after 8 years of follow up, parathyroid ultrasound did not detect enlarged parathyroid glands.

\section{Discussion}

A Chinese MEN1 pedigree was investigated in this study. $M E N 1$ gene sequence analysis revealed the presence of a heterozygous mutation c.825-1G>A (IVS 5-1 G>A). Two carriers were identified and followed in the pedigree. The family was followed up for over 20 years.

Since the cloning of the gene in 1997, 1,336 mutations and 24 normal allelic variants had been described by 2008 . Intron 5 mutations were reported in two different studies (935-1G>C) $(11,12)$. A Japanese 66-year-old male presenting with prolactinoma, a gastrin-secreting carcinoid tumor and multiple parathyroid lessons. The mutation caused transcription skipping of exon 6 (88 bp), resulting in a frame shift mutation and premature termination codon. Raghavan et al (12) presented another case of a 35-year-old with multiple gastrinomas, pituitary microadenoma, hyperparathyroidism, a serum gastrin level of 2,000 pg/ml (normal, $<100 \mathrm{pg} / \mathrm{ml}$ ), and markedly elevated serum calcium and PTH. The patient underwent 3.5/4 parathyroid gland excision was performed and pituitary microadenoma was treated with bromocriptine. The clinical outcome and follow up of the patients was not mentioned in these two case reports. The proband in the present study presented with a mutation that was different but in the same site as the mutations of these two cases. The proband had a clear family history and presented with gastrinoma, pituitary tumor, parathyroid hyperplasia, thymoma and a lung malignant carcinoid tumor. Thus, this suggests that mutations in this site cause a similar phenotype.
As reported by the National Cancer Institute summit meeting in 2007 on GEP-NETs (13), standardized clinical management is often limited by different aspects of the disease. For example, the relative rarity, the limited understanding of tumor biology and behavior, heterogeneous clinical presentation, and the lack of prospectively evaluated risk stratification systems, has resulted in incomplete implementation of staging systems. Evidence for proper follow up and controlled study of treatment efficacy are poor $(14,15)$. Patients with MEN1 have a decreased life expectancy, and the outcomes of current treatments, which are generally similar to those for the respective tumors occurring in non-MEN1 patients, are not as successful. This is due to the presence of multiple tumors, which may be larger, more aggressive, and resistant to treatment, as well as the presence of metastases (16). These characteristics of MEN1 tumors thereby render it difficult to achieve a successful cure. For example, patients with MEN1 often develop multiple submucosal duodenal gastrinomas, thereby reducing surgical cure rates compared with similar sporadic solitary tumors, (17). Patients with MEN1 also develop multiple parathyroid tumors, and subtotal parathyroidectomy has been shown to result in persistent or recurrent hypercalcemia within 10 years in $20-60 \%$ of patients with MEN1, as opposed to $4 \%$ in patients without MEN1 (18). The proband underwent four surgical procedures and was followed up for 20 years. She died of accidental trauma and had a relatively stable illness course. This indicates that although multiple organs and systems were involved in MEN1, MEN1 tumors should be considered surgically curable diseases if the patients are properly cared for by multidisciplinary teams comprising relevant specialists with experience in the diagnosis and treatment of patients with endocrine tumors. Recent studies support this hypothesis. For example, duodenal gastrinoma in patients with MEN1 could be considered a surgically curable disease by pancreaticoduodenectomy with a high cure rate (19).

In conclusion, an MEN1 pedigree was reported in the present study. The clinical course of the proband was followed up for 20 years. The clinical course of the patient indicates that although MEN1 is a complex disease involving multiple organs and systems, patients with MEN1 may have a relatively benign prognosis after proper treatment. MEN1 tumors should thus be considered as surgically curable. 


\section{Acknowledgements}

This study was supported by Professor Xunwu Meng. The MEN1 gene analysis was conducted in Peking Union Medical College Hospital. The follow up in April 2012 was conducted in Beijing Chaoyang Hospital.

\section{References}

1. Chandrasekharappa SC, Guru SC, Manickam P, Olufemi SE, Collins FS, Emmert-Buck MR, Debelenko LV, Zhuang Z, Lubensky IA, Liotta LA, et al: Positional cloning of the gene for multiple endocrine neoplasia-type 1. Science 276: 404-407, 1997.

2. Lemmens I, Van de Ven WJ, Kas K, Zhang CX, Giraud S, Wautot V, Buisson N, De Witte K, Salandre J, Lenoir G, et al: Identification of the multiple endocrine neoplasia type 1 (MEN1) gene. The European Consortium on MEN1. Hum Mol Genet 6: 1177-1183, 1997.

3. Pannett AA and Thakker RV: Somatic mutations in MEN type 1 tumors, consistent with the Knudson 'two-hit' hypothesis. J Clin Endocrinol Metab 86: 4371-4374, 2001.

4. Carling T: Multiple endocrine neoplasia syndrome: Genetic basis for clinical management. Curr Opin Oncol 17: 7-12, 2005.

5. Leotlela PD, Jauch A, Holtgreve-Grez $\mathrm{H}$ and Thakker RV: Genetics of neuroendocrine and carcinoid tumours. Endocr Relat Cancer 10: 437-450, 2003.

6. Brandi ML, Gagel RF, Angeli A, Bilezikian JP, Beck-Peccoz P, Bordi C, Conte-Devolx B, Falchetti A, Gheri RG, Libroia A, et al: Guidelines for diagnosis and therapy of MEN type 1 and type 2. J Clin Endocrinol Metab 86: 5658-5671, 2001.

7. Lemos MC and Thakker RV: Multiple endocrine neoplasia type 1 (MEN1): Analysis of 1336 mutations reported in the first decade following identification of the gene. Hum Mutat 29: 22-32, 2008

8. Eckel F, Jelic S and ESMO Guidelines Working Group; Billiary cancer: ESMO clinical recommendation for diagnosis, treatment and follow-up. Ann Oncol 20 (Suppl 4): 46-48, 2009.

9. Mailman MD, Muscarella P, Schirmer WJ, Ellison EC, O'Dorisio TM and Prior TW: Identification of MEN1 mutations in sporadic enteropancreatic neuroendocrine tumors by analysis of paraffin-embedded tissue. Clin Chem 45: 29-34, 1999.
10. Nagamura Y, Yamazaki M, Shimazu S, Sano K, Tsukada T and Sakurai A: A novel splice site mutation of the MEN1 gene identified in a patient with primary hyperparathyroidism. Endocr J 59: 523-530, 2012

11. Hai N, Aoki N, Shimatsu A, Mori T and Kosugi S: Clinical features of multiple endocrine neoplasia type 1 (MEN1) phenocopy without germline MEN1 gene mutations: Analysis of 20 Japanese sporadic cases with MEN1. Clin Endocrinol (Oxf) 52: 509-518, 2000.

12. Raghavan R, Shah S, Kondkar AA, Dherai AJ, Desai D, Chauhan P, Lala M and Ashavaid TF: MEN1 935-1G>C splicing mutation in an Indian patient with multiple endocrine neoplasia type 1. Mol Diagn Ther 11: 129-131, 2007.

13. Modlin IM, Moss SF, Chung DC, Jensen RT and Snyderwine E: Priorities for improving the management of gastroenteropancreatic neuroendocrine tumors. J Natl Cancer Inst 100: 1282-1289, 2008.

14. Machens A, Schaaf L, Karges W, Frank-Raue K, Bartsch DK, Rothmund M, Schneyer U, Goretzki P, Raue F and Dralle H: Age related penetrance of endocrine tumours in multiple endocrine neoplasia type 1 (MEN1): A multicentre study of 258 gene carriers. Clin Endocrinol (Oxf) 67: 613-622, 2007.

15. Ehehalt F, Saeger HD, Schmidt CM and Grützmann R: Neuroendocrine tumors of the pancreas. Oncologist 14: 456-467, 2009.

16. Thakker RV, Newey PJ, Walls GV, Bilezikian J, Dralle H, Ebeling PR, Melmed S, Sakurai A, Tonelli F, Brandi ML, et al: Clinical practice guidelines for multiple endocrine neoplasia type 1 (MEN1). J Clin Endocrinol Metab 97: 2990-3011, 2012.

17. Imamura M, Komoto I, Ota S, Hiratsuka T, Kosugi S, Doi R, Awane $\mathrm{M}$ and Inoue $\mathrm{N}$ : Biochemically curative surgery for gastrinoma in multiple endocrine neoplasia type 1 patients. World J Gastroenterol 17: 1343-1353, 2011.

18. Schreinemakers JM, Pieterman CR, Scholten A, Vriens MR, Valk GD and Rinkes IH: The optimal surgical treatment for primary hyperparathyroidism in MEN1 patients: A systematic review. World J Surg 35: 1993-2005, 2011.

19. Lopez CL, Falconi M, Waldmann J, Boninsegna L, Fendrich V, Goretzki PK, Langer P, Kann PH, Partelli S and Bartsch DK: Partial pancreaticoduodenectomy can provide cure for duodenal gastrinoma associated with multiple endocrine neoplasia type 1. Ann Surg 257: 308-314, 2013. 